\title{
Perfis da província e máscaras da modernidade: uma leitura da correspondência de Gilberto Freyre com Manuel Bandeira, José Lins do Rego e Rodrigo Melo Franco de Andrade*
}

\author{
Provincial sketches and masks of modernity: an interpretation of the Gilberto Freyre's \\ correspondence with Manuel Bandeira, José Lins do Rego and Rodrigo Melo Franco de Andrade
}

Silvana Moreli Vicente Dias

Universidade de São Paulo - São Paulo - São Paulo - Brasil

$\diamond$

\begin{abstract}
Resumo: O objetivo deste artigo é interpretar a epistolografia de Gilberto Freyre com base no conceito de persona ou máscara. Dialogando com escrita mais grave, que beira o paroxismo e a tragédia pessoal e coletiva, de José Lins do Rego, bem como com as formas literárias aparentemente descomprometidas presentes nas cartas trocadas com Manuel Bandeira e Rodrigo Melo Franco de Andrade, articulam-se distintas personae na correspondência do ensaísta. Serão colocadas em pauta facetas ambíguas do escritor Gilberto Freyre, ao lado da tentativa de se refletir sobre aspectos da modernidade alternativa ou provinciana que lhes são subjacentes. Portanto, será possível perceber como os paradoxos presentes no ensaio social de Freyre ligam-se também às imagens contraditórias inscritas no tecido epistolar.

Palavras-chave: Gilberto Freyre (1900-1987); Manuel Bandeira (1886-1968); José Lins do Rego (1901-1957); Rodrigo Melo Franco de Andrade (1898-1969); Modernismo brasileiro

Abstract: This article aims to interpret the Gilberto Freyre's epistolography taking as a basis the concept of persona or mask. Different personae are articulated in the correspondence of the essayist dialoguing with the more grave writing of José Lins do Rego, which come near to the paroxysm and the personal and the collective tragedy, as well as with the more humorous literary forms that are present in the letters exchanged with Manuel Bandeira and Rodrigo Melo Franco de Andrade. Then, ambiguous facets of Gilberto Freyre's work will be seen, and one will reflect on aspects of the alternative or provincial modernity that are subjacent to them. Hence it will be possible to observe how these paradoxes, which constitute the Freyre's social essay, are linked to the contradictory images that also mark his epistolary practice.
\end{abstract}

Keywords: Gilberto Freyre (1900-1987); Manuel Bandeira (1886-1968); José Lins do Rego (1901-1957); Rodrigo Melo Franco de Andrade (1898-1969); Brazilian Modernism

\section{Gilberto Freyre em cartas: o eu e seu(s) nó(s)}

Em uma reflexão recentemente publicada sobre o texto epistolar e sua relação com a forma romanesca, o escritor Cristovão Tezza faz considerações instigantes para que adentremos na natureza dinâmica e ambígua da carta como forma literária significativa para se compreenderem figurações do homem moderno: "Em suma, há uma essência romanesca na estrutura epistolar [...], há uma espinha modelar que, a essa altura, já é quase independente da própria existência física das cartas" (TEZZA, 2012, p. 170). Sem negar sua dimensão histórica, a carta é composição, traz uma interação de vozes, uma urgência narrativa que leva a estabelecer sentidos a partir de uma intercomunicação potencialmente estimulada, a tensão do agora - o outro, meu destinatário, é um presente paradoxalmente ausente-, criando personagens, exer-

\footnotetext{
* A pesquisa que resultou neste artigo obteve, em diferentes momentos, financiamento da FAPESP e da CAPES. Para sua realização, foi fundamental o apoio da Fundação Gilberto Freyre, que forneceu cópias digitalizadas e fotocópias das cartas de Gilberto Freyre, Manuel Bandeira e José Lins do Rego. Os documentos originais foram consultados, respectivamente, na Fundação Gilberto Freyre (PE), na Fundação Casa de Rui Barbosa (RJ) e no Museu José Lins do Rego $(\mathrm{PB})$.
} 
citando a opinião direta, matizando julgamentos, experimentando um jogo de representação, configurando-se como uma prática concreta de escrita em que se sobrelevam o valor do indivíduo e suas vicissitudes em muitos momentos. Para Tezza, é a solidão do indivíduo, "o seu desamparo, que criou o gênero epistolar moderno" (TEZZA, 2012, p. 170). Tensões entre documento e objeto estético, entre real e ficcional, entre objetividade e subjetividade, entre o indivíduo e o coletivo estão no cerne da prática epistolar de escritores brasileiros do século $\mathrm{XX}$, e tais movimentos ambíguos atualizam-se, de muitos modos, no tecido multidimensional das cartas.

Mais ainda, se, por um lado, na trilha de Tezza, pode haver a exaltação do indivíduo quando se escrevem cartas - debatendo-se em dúvidas, pesquisando novas formas, articulando esteticamente diferentes aspectos de uma crise pessoal -, por outro, com o modernismo brasileiro, a correspondência de escritores sofreu modificações significativas rumo ao adensamento de questões coletivas. Desenvolveram-se, no modernismo, intensas reflexão e discussão que colocaram o Brasil e sua cultura no centro do debate, por meio de missivas empenhadas em construir uma imagem moderna do país. ${ }^{1}$ Portanto, combinaram-se discursos a enfatizar a laboriosa construção da identidadeeu e discursos que dão relevo a experiências coletivas não raro díspares, de ressonância pública, uma identidadenós multifacetada, para citar Norbert Elias (Cf. ELIAS, 1994) $)^{2}$. E, à medida em que o interesse nacional habitou o tecido epistolar, no limite, essa identidade de caráter coletivo misturou-se a figurações do caráter nacional.

Para situar melhor alguns debates em torno do epistolário de escritores do século $\mathrm{XX}$, dois grandes desafios modernistas - para Otto Maria Carpeaux,

\footnotetext{
1 Segundo Júlio Castañon Guimarães: “As modificações estéticas trazidas pelo modernismo têm como suas principais características a liberdade em relação aos moldes até então vigentes, a liberdade de pesquisa, a liberdade de criação, com a busca de elementos nacionais, e assim por diante. Também a correspondência refletirá esses aspectos, não apenas em termos de que tratará deles, mas em sua própria formulação. A carta perde a formalidade que se encontra até essa época; torna-se efetivamente troca de ideias, informações, como substituto efetivo da conversa." (GUIMARÃES, 2004, p. 24)

2 A reflexão de Norbert Elias sobre a relação identidade-eu e identidadenós situada historicamente converge, de algum modo, para a percepção de Gilberto Freyre sobre a progressiva fragmentação do eu na modernidade: "Desde a Idade Média europeia, o equilíbrio entre a identidade-eu e a identidade-nós passou por notável mudança, que pode ser resumidamente caracterizada da seguinte maneira: antes a balança entre as identidadesnós e eu pendia maciçamente para a primeira. A partir do Renascimento, passou a pender cada vez mais para a identidade-eu. Mais e mais frequentes se tornaram os casos de pessoas cuja identidade-nós enfraqueceu a ponto de elas se afigurarem a si mesmas como eus desprovidos do nós. [...] A identidade-nós das pessoas, embora decerto continuasse sempre presente, passou então, muitas vezes, a ser obscurecida ou ocultada, em sua consciência, pela identidade-eu." (ELIAS, 1994, p. 161).

3 Dois volumes reúnem a edição de cartas escritas por Gilberto Freyre: FREYRE, 1978, com organização de Sylvio Rabello; e EM FAMÍLIA, 2005, com organização de Ângela de Castro Gomes [correspondência ativa e passiva]
}

dificilmente compatíveis - aparecem na escrita de cartas nesse período, prática presente em projetos compartilhados: de um lado, havia a necessidade de criar "uma nova poesia e arte realmente nacionais, brasileiras", e, de outro, empregar "recursos das vanguardas europeias, da França e da Itália." (CARPEAUX, s.d., p. 129). Considerando-se que a forma e suas tensões são eminentemente modernas, a matéria sobre a qual a carta reflete e que de algum modo refrata pode complexificar-se ao se empreenderem leituras a contrapelo da experiência de modernização hegemônica, como ocorre, por exemplo, em Gilberto Freyre, Manuel Bandeira e José Lins do Rego. As cartas desses "provincianos" recordam alguns limites de projetos em gestação no Brasil ao longo das primeiras décadas do século $\mathrm{XX}$, ao mesmo tempo em que apontam para a viabilidade de experiências alternativas que acabaram por, de algum modo, marcar vozes altissonantes do modernismo brasileiro sobretudo à época, a despeito de uma manifesta - e, em alguma medida, proposital - feição anacrônica. Nesse sentido, é como se procurassem elaborar alternativas ao modelo cosmopolita predominante, propenso à abstração, o qual, para recuperar formulação do crítico italiano Alfonso Berardinelli, poderia ser definido a partir de conceitos como "desenraizamento, fragmentação, primitivismo, aspiração extrema ao essencial ao preço de reduzir templos e palácios a pedacinhos minúsculos, migalhas estéticas" (BERARDINELLI, 2007, p. 85).

Uma das figuras mais atuantes no nosso modernismo, Gilberto Freyre tem vasta correspondência com escritores, intelectuais, artistas e políticos brasileiros e estrangeiros, em grande parte ainda não publicada. ${ }^{3}$ As cartas de Freyre são textos que apresentam paradoxos do gênero epistolar na modernidade: aprofundam uma dimensão pública que lhes é inerente, interessada em construir novas formas de ênfase regional, tradicional, provinciana -, e ao mesmo tempo testemunham, com tom íntimo inequívoco, o embate do indivíduo com seu presente. Em parte, desenhase a imagem de um leader de província, imbuído de um projeto coletivo de incontáveis faces; noutra, o rosto de um sujeito em muitos momentos desamparado, solitário, na encruzilhada, buscando (re)compor a forma e o fundo para parecer autêntico, para articular, de forma coerente, uma identidade-eu e uma identidade-nós.

Procuram-se, assim, trilhas alternativas aos (des) caminhos da modernização no país, que provocariam, segundo o autor, uma espécie de alheamento do sujeito em seu próprio território, formas modernas "de fachada". E, recuperando mais uma vez Norbert Elias de $A$ sociedade dos indivíduos, quando empregamos "nós", sobretudo na correspondência, a multiplicidade de camadas a que o termo se refere aponta para diversos tipos de relação: família, amigos, cidades, regiões natais, 
nações, humanidade, de coloração afetiva tanto mais forte quanto mais próximo à experiência específica se está. Para Freyre, essas esferas de convivência se misturam, se interpenetram, se alimentam a todo momento.

Como escritor e intelectual que pensa as urgências do seu tempo, Gilberto Freyre também faz circular nomes ligados aos movimentos de vanguarda europeus e norteamericanos - conhecidos após longo período de formação acadêmica nos Estados Unidos, entre 1918 e 1923 - como modo de dinamizar um olhar particular para a cultura regional, local, da província, questionando e exaltando as possibilidades intercomunicativas apesar de inúmeros obstáculos e descompassos - fossem eles econômicos, sociais e culturais - que separariam, por exemplo, Recife de Nova York e Paris.

$\mathrm{Na}$ leitura de uma missiva, ademais, aspectos sociais e figurações da intimidade mesclam-se a ponto de impossibilitarem separações nítidas entre um e outro. Os movimentos da sociedade civil organizada são objetos de reflexão constante nas cartas; indivíduos conjeturam, por exemplo, sobre entraves políticos locais e nacionais ou sobre o mercado editorial em franca consolidação, de que trazem inúmeros exemplos as cartas de Freyre trocadas com Bandeira, José Lins e Rodrigo Melo Franco de Andrade. Destacam-se redes formadas por indivíduos em relação, nunca isolados. Nesse sentido, a correspondência humaniza o indivíduo ao vê-lo como "nó(s)" em convivência, imerso no cotidiano da vida prática, jamais como uma substância livre de vicissitudes - em outras palavras, tramas que revelam os nós e suas conexões problemáticas, um jogo dinâmico de máscaras.

Trata-se, pois, de uma perspectiva relacional - e não substancialista - fortemente operada nas escritas literárias de Gilberto Freyre e seus correspondentes, confirmada pelo modo singular como se põe diante de diferentes interlocutores, produzindo distintos efeitos de presença - o que também faz lembrar, por exemplo, o aspecto dramático presente na análise social levada a cabo por Erving Goffman (1985), para quem o papel desempenhado pelo indivíduo, na sociedade, depende sempre dos papéis desempenhados por outros. Assim, um modo de se pensarem esses autores passa também pela interpretação de suas cartas, nas quais as figurações dos indivíduos e suas máscaras, carnavalizadas ou trágicas, são elementos que permitem ressaltar sentidos presentes em sua própria obra.

\section{A face carnavalizada da província}

Nesta leitura da epistolografia de Gilberto Freyre, dois conjuntos a serem destacados são as cartas trocadas com José Lins do Rego e com Manuel Bandeira. Cartas enviadas a Rodrigo Melo Franco de Andrade também serão apresentadas, principalmente pelo diálogo que estabelecem com a correspondência trocada com Bandeira. Esta reflexão, por sua vez, se pautará pelo conceito de persona, permitindo que se observem figurações problemáticas, gestos, rastros, desvios do indivíduo que se expressa por meio de uma missiva em uma espécie de interação performática com seu destinatário.

Gilberto Freyre se aproximou de Manuel Bandeira precisamente em 1925, por meio de uma troca epistolar bastante descontraída. A amizade, em princípio motivada por afinidades literárias e posteriormente aprofundada a ponto de incluir uma íntima convivência em família, só se encerraria com a morte do poeta. Freyre estabelece uma postura de respeito com relação a Bandeira. E, se pudéssemos apontar uma tonalidade dominante nesse conjunto epistolar, esta poderia ser a da "cordialidade", segundo definição de Freyre em Sobrados e mucambos, de 1936. ${ }^{4}$ Nesse sentindo, a formação mestiça do brasileiro teria permitido que traços expansivos marcassem a relação interpessoal, simpatia agregadora presente no próprio tecido da carta, visto que as missivas trocadas por Freyre e Bandeira mantêm uma relação muito estreita com as formas de viés comunicativo, ligadas à vida comezinha, com o diálogo desenvolto, adensamento lhano este que se combina com o riso leve e descontraído que teria marcado vertente significativa do modernismo no Brasil.

Uma cosmovisão carnavalizante, nutrida pela oralidade, pelo dialogismo, pela perspectiva do mundo invertido, desestabilizado, pelo ludismo está presente no conjunto. ${ }^{5}$ Inclusive, ela mesma contaminaria a forma estética da obra canônica, como é sobretudo o caso de Manuel Bandeira com Libertinagem (1930) e Crônicas da província do Brasil (1936), já escritos após o contato "subversor" com Freyre. Leia-se como o poeta se revela sugestivamente tocado, em carta de 1925, pelo poema de Freyre "Bahia de Todos os Santos e de quase todos os pecados": "Teu poema, Gilberto, será a minha eterna dor de corno. Não posso me conformar com aquela galinhagem tão gozada, tão sem vergonhamente lírica [...]. Sacana!". ${ }^{6}$

\footnotetext{
4 No capítulo "Ascensão do bacharel e do mulato", de Sobrados e mucambos, Gilberto Freyre utiliza o termo: "A simpatia à brasileira - o homem simpático de que tanto se fala entre nós, o homem 'feio, sim, mas simpático' e até 'ruim ou safado, é verdade, mas muito simpático'; o 'homem cordial' a que se referem os Srs. Ribeiro Couto e Sérgio Buarque de Holanda - essa simpatia e essa cordialidade, transbordam principalmente do mulato. Não tanto do retraído e pálido como do cor-derosa, do marrom, do alaranjado. Ninguém como eles é tão amável; nem tem um riso tão bom; uma maneira mais cordial de oferecer ao estranho a clássica xicrinha de café; a casa; os préstimos. Nem modo mais carinhoso de abraçar e de transformar esse rito como já dissemos orientalmente apolíneo de amizade entre homens em expansão caracteristicamente brasileira dionisiacamente mulata, da cordialidade." (FREYRE, 2003, p. 791).

5 Para a percepção do sentido em que os termos "carnavalização" e "dialogismo" são empregados, cf. BAKHTIN, 1987; BAKHTIN, 1981.

6 Carta de Manuel Bandeira a Gilberto Freyre, com datação "Rio de Janeiro, 4 de junho [de 1927]".
} 
E, vale ainda dizer, em uma possível dialética de mascaramento e desnudamento própria ao texto epistolar, em Bandeira e Freyre sobressai uma espécie de mascaramento dinâmico que trilha, porém, o autêntico, ${ }^{7}$ ou seja, o aspecto singular das intuições provincianas, em suas experiências táteis, olfativas, auditivas, gustativas e visuais não reproduzíveis, a especificidade da memória da infância, de uma experiência inaugural da história. De fato, "o provinciano", presente na correspondência, ganharia tamanho adensamento nos anos seguintes que passaria a habitar também a obra dos escritores. Veja-se, por contraste, uma carta de Freyre datada dos anos do exílio nos Estados Unidos, em 1931; e uma crônica de Bandeira, de 1933:

E um desses dias, aí chegará num cargueiro ou na $3^{\mathrm{a}}$ classe de um alemão este provinciano (cosmopolita, cigano, romântico, modern, intellectual, radical, reacionário, revolucionário, ortodoxo, Raul Dos Passos - (irmão do Dos Passos, daqui, o de Three soldiers). Seraphim Jung, Jorge Rialto, Antonio Ricardo etc. etc. - oxoniano, M. A. Columbia, Stanfordiano, etc. etc. etc.). [...] Entretanto, eu posso raspar tudo isso de mim? Na província, a nostalgia do grande mundo não me deixará de todo; as memórias, que estavam secando, abriram-se de novo em verdadeiras feridas. Meu caro Flag, desculpe tanta literatura; não é só literatura. ${ }^{8}$

A seguir, trecho de crônica de Manuel Bandeira:

Sou provinciano. Com os provincianos me sinto bem. Se com estas palavras ofendo algum mineiro requintado peço desculpas. [...] É provinciano, mas provinciano do bom, aquele que está nos hábitos do seu meio, que sente as realidades, as necessidades do seu meio. Esse sente as excelências da província. Não tem vergonha da província - tem é orgulho. Conheço um sujeito de Pernambuco, cujo nome não escrevo porque é tabu e cultiva com grandes pudores esse provincianismo. Formou-se em sociologia na Universidade de Colúmbia, viajou a Europa, parou em Oxford, vai dar breve um livrão sobre a formação da vida social brasileira... Pois timbra em ser provinciano, pernambucano, do Recife. Quando dirigiu um

\footnotetext{
A autenticidade pode ser associada ao conceito de "aura", na linha de Walter Benjamin: "Mesmo na reprodução mais perfeita, um elemento está ausente: o aqui e agora da obra de arte, sua existência única, no lugar em que ela se encontra. É nessa existência única, e somente nela, que se desdobra a história da obra. [...] O aqui e agora do original constitui o conteúdo da sua autenticidade, e nela se enraíza uma tradição que identifica esse objeto, até os nossos dias, como sendo aquele objeto, sempre igual e idêntico a si mesmo. A esfera da autenticidade, como um todo, escapa à reprodutibilidade técnica, e naturalmente não apenas à técnica." (BENJAMIN, 1985:167).

8 Cf. cap.3 de minha tese de doutorado Cartas provincianas, Documento 11, com datação "Stanford, 9 de junho de 1931". In: VICENTE, 2007.

9 Segundo nota de edição em Andorinha, andorinha, o texto foi escrito para o Estado de Minas, Belo Horizonte, 12 mar. 1933.
}

jornal lá, fez questão de lhe dar feitio e caráter bem provincianos. Nele colaborei com delícia durante uns dois anos. Foi nas páginas da A Província que peguei este jeito provinciano de conversar. [...] (BANDEIRA, 1974 , p. 668$)^{9}$

A máscara do provinciano, que aos poucos adentraria na obra de Bandeira, é traço epistolar de Freyre que marca em especial suas cartas da década de 1920 e início da década de 1930, quando, na condição de intelectual outsider que procura escrever sua obra-prima (que seria Casa-grande \& senzala, lançada em 1933), aborda, com distanciamento irônico, sua condição de duplamente deslocado - na "província" de Pernambuco (e não mais nos Estados Unidos, onde residira), sem emprego, inspirado por projetos incertos, ainda sofrendo a sombra do exílio e do isolamento. Observe-se, portanto, como, ao lado de Bandeira, Rodrigo Melo Franco de Andrade (também residente no Rio de Janeiro, então capital federal) tornase um interlocutor modelar para um exercício lúdico e, ao mesmo tempo, consequente com o termo "provinciano":

\begin{abstract}
Meu caro Rodrigo:
Recebi sua carta na qual V. tanto anima o provinciano a continuar o trabalho. Este vai indo bem: já outras 50 páginas estão prontas mas não sei como mande. A época não é das mais favoráveis a literatos com medo de perder no Correio ou às mãos da censura ou da polícia suas preciosas obras primas. [...] Felizmente vejo que não há perigo do Ariel me revelar à elite brasileira que ao meu ver deve pacientemente aguardar o aparecimento da coisa em livro. (É um caprichozinho de provinciano). (FREYRE, 1978, p. 254)
\end{abstract}

Em outra carta, igualmente não datada, Freyre escreve a Rodrigo revelando mais uma vez os "bastidores de privação" por trás de Casa-grande \& senzala:

\begin{abstract}
Minha vida tem sido uma aventura quase diária - às vezes não havendo fruta nenhuma para vender, nem comprador de livro ou quadro, mas tenho conservado um sense of humour de que me espanto às vezes. É verdade que outras tenho vontade de give up. Felizmente, ou infelizmente, agora ando com um amor muito romântico: desses provincianos. [...] Sinceramente estou me achando cada vez menos Pará [...]. Depois do livro pronto e publicado, irei, sem as obrigações outras de viver entre livros, cuidar da vida e estou me inclinando muito à ideia de um sítio e de criar galinhas. Um sítio que eu arrendaria, talvez mesmo este do Carrapicho. (FREYRE, 1978, p. 249-250)
\end{abstract}

Retornando à correspondência de Freyre com Bandeira, em carta de 28 de dezembro de 1934, a persona epistolar do "provinciano" liga-se ao exercício estético, à expressão literária. A máscara provinciana, portanto, possibilitaria religar singularmente o homem Freyre a 
sua origem, a seu cotidiano, à vida comezinha, à família, ao autêntico da experiência. Aliás, o exercício subjetivo é marcante quando se configura a imagem do intelectual público emergente, que já começava a colher os frutos do sucesso repentino causado por seu grande livro:

Bons anos! A você e às boas amigas Blank, inclusive a pequenininha - Bons Anos! Estou com saudades. Você não dá um ar de sua graça, deixa o provinciano sem notícias, fora das novidades da Metrópole. Mas o provinciano não esquece você nem as boas amigas de Santa Teresa. O provinciano atravessou um ano que não foi dos melhores de sua vida - doente quase todos estes últimos seis meses. Felizmente parece que voltou agora ao seu "equilíbrio biológico". O provinciano está feliz no casarão velho onde mora agora com a família, numa puxada assobradada - puxado, dizem os requintados de Capiberibe, mas nós provincianos das margens do Capibaribe dizemos puxada. (Casa velha e boa, bem boa, mas não deixo de ter saudades do K. onde esperava viver toda a vida.) O provinciano está sentimental. O provinciano tem estado horrivelmente sentimental, até mesmo atacado de self-pity. Já esteve uma vez assim e curou-se lendo Nietzsche. Agora, com tanto trabalho, não tem recorrido a Nietzsche: tem recorrido ao fumo. Charuto, cigarro. Mas cigarro só inglês, que o provinciano tem coisas de requintado misturadas com o seu plebeísmo de club das Pás e festas de igreja. Vou deixar essa história de "o provinciano" que está virando literatura e retomar o meu eu. ${ }^{10}$

Portanto, o "provinciano", com suas incontáveis faces, funcionaria como uma espécie de máscara epistolar dinâmica e relacional. De incontestável feição anacrônica, a província recorda a vontade de ligar-se a uma região, a uma história, a uma experiência palpável, como modo de vida e de escrita alternativo ao modelo cosmopolita dominante. A crônica da vida cotidiana presente em uma carta poderia indicar, portanto, ao lado da obra efetivamente publicada, tensões significativas entre vida e forma literária, estética e experiência.

\section{O vulto trágico da província}

Por sua vez, a correspondência de Gilberto Freyre com José Lins, escritor cuja produção se tornaria símbolo da decadência do regime patriarcal nordestino, avulta não só pela quantidade, mas também pela diversificação e profundidade dos assuntos ali tratados. Nela, a aparência de objetividade na relação entre iguais se contorce a tal ponto que, novamente, outro conceito freyriano, o "equilíbrio de antagonismos" - extensamente trabalhado

\footnotetext{
${ }^{10}$ Cf. cap. 3 de minha tese de doutorado Cartas provincianas, Documento 16, com datação "Recife, 28 de dezembro de 1934". In: VICENTE, 2007.

11 Para uma leitura sobre a tradição familista e androcêntrica dos discursos sobre a amizade no Ocidente, cf. DERRIDA, 2005.
}

em Casa-grande \& senzala -, vem lançar luz sobre as forças paradoxais e dinâmicas que podem constituir o sujeito, a troca entre indivíduos e, por extensão, o processo social.

Nesse conjunto, há uma força tendente ao centramento, ao encrespamento, ao silêncio. O "nós" coletivo, mais presente na face "carnavalizada" da província, com suas crônicas mundanas, é minorado, ao passo que a relação entre os sujeitos, muitas vezes tensionada, permite explorar a expressão de indivíduos em crise. E, nesse contexto, não sobressai um discurso que enfatiza a fraternidade, a relação entre iguais - que, no limite, poderia indicar um projeto político de cunho liberal. ${ }^{11}$ Aliás, como afirma Jessé Souza, para Freyre igualdade política e econômica nunca foram princípios importantes; para o ensaísta da província, seria mais relevante perceber as formas de integração e comunicação recíproca entre diferentes (Cf. SOUZA, 2000, p. 212), o que ficaria evidente inclusive na relação entre os epistológrafos Freyre e José Lins enquanto o primeiro é mais dinâmico, antropofágico, cosmopolita e vanguardista, embora "provinciano", o segundo oferece quase sempre um contraste ao riso, à ironia e à descontração, com sua fácies provinciana mais autocentrada e taciturna.

Além desse "equilíbrio dinâmico" entre indivíduos que dialogam, pautado, em certo sentido, pela tristeza, o próprio teor dessas cartas vai de encontro ao mundo invertido, carnavalesco, eterno convite aos prazeres da boemia presente nas cartas trocadas entre Freyre e Bandeira. Desse modo, os movimentos de integração e equilíbrio com o meio social podem ser observados nos excertos a seguir; enquanto a atmosfera de festa é bastante presente nas cartas de Freyre e Bandeira, a mesma é censurada em Freyre e José Lins, como na carta com provável datação em 14 de setembro de 1926:

Já recebeu notícias de Ulysses? Pondo de lado qualquer vontade de fazer-lhe de patriarca ou de [decurião] de bons costumes, penso que você deve ir quanto antes para o Recife. Você me perdoe o ar [materno] que me envolve dizendo isto. O fato é que as noitadas, por mais pitorescas que sejam podem [perturbar] a sua economia, como dizem os parnasianos.

Censura à qual Freyre responde do seguinte modo em carta de 22 de setembro de 1926 :

Meu caro Lins:

Recebi agora mesmo sua carta. Estou na maré de receber cartas. Ontem - 15 ou 16 de Pernambuco - da família e Anibal - e dos Estados Unidos. Sua carta vem atrasada. Você ainda receberá esta? Eu não sei. Você demora? Se demorar muito, já não me avistará por aqui. Ontem telegrafei que me mandassem por telegrama dinheiro para voltar. Agora é que posso 
voltar. Antes eu não podia voltar. Parece que você não compreende isso: que eu não podia voltar antes. Parece que você pensa que eu fiquei por aqui sob o encanto das noitadas. Eu não quero dizer que sou "um forte" ou qualquer coisa assim. Eu sou apenas um Nestor Vítor em botão - se for tanto. Lins, você sabe que eu tinha de ficar aqui sem ter um lugar interessante para onde ir. Você nunca me ofereceu sua casa. A casa de Tio Juca tem uma mobília horrível. Na casa do arquiteto há uma vitrola que põem a tocar e conversa requintada; e toda essa gente não me compreende nem um pouquinho. E [coisa] fingir, transigir, contemporizar. De modo que é mais suportável beber um pouco, rolar um pouco pelos cafés, ouvir o [preto] de São José tocar Pandeiro e ver Sérgio ${ }^{12}$ vomitar literariamente vômitos esverdeados. E ouvir Pixinguinha e Patrício ${ }^{13}$ - deliciosos. [...] Outro dia estive na casa do querido Bandeira com Sérgio. Sérgio é interessante. O Prudente ${ }^{14}$ também. Dodô ${ }^{15}$ não tenho visto. Nem Ronald ${ }^{16}$ depois daquela vez. Não sei ainda se ao receber o dinheiro largarei logo para o Recife ou darei um pulo a São Paulo. Eu estou cada vez mais fraco, necessitando daquele regímen de leite de minha mãe. E do meu quarto. Da minha cama. De tudo aquilo.

Gilberto

A dinâmica social de um mundo decadente, pautado pela desordem, é sentida como uma ameaça, da qual os indivíduos procuram se apartar. Afastando-se do jogo das máscaras contíguo ao universo de "paraíso carnavalesco" de Freyre e Bandeira, de personae epistolares com base nas quais se chocam múltiplas figurações, a cosmovisão dominante nas missivas de Freyre e José Lins aproximase de um sentido trágico. O desnudamento tem certa radicalidade, beirando o narcisismo claustrofóbico, o limite do medo da morte, da destruição de tudo, da situação sem saída, da qual sobretudo Freyre procura se desviar.

Decantando um dos sentidos derivados do conceito clássico de persona, ${ }^{17}$ é como se, no horizonte, o aprofundamento do fundo pudesse fazer estilhaçar o "rosto", a superfície, aquilo que permite que o eu se reconheça como indivíduo, singularidade, máscara termo empregado em sentido não negativo, ou seja, não como dissimulação ou disfarce, mas como espécie de película, ainda que mutilada e recomposta, por meio da qual o eu se expressa e se revela, e que, portanto, possibilita a interação, mesmo que problemática, com o outro.

Acabo de receber sua carta - sem data: aquela em que fala da visita ao velho Oiticica, num tão acolhedor engenho, bem à beira de um rio como deve ser todo engenho que se preza. Decididamente houve carta sua para mim que se perdeu - convindo que você registrasse suas cartas. Eu hoje já não me correspondo com quase ninguém, tenho deixado que a distância vá empalidecendo muita amizade feita por este mundo afora, onde tenho deixado alguma cousa de mim - pois sou, com todo o esforço em contrário, um mutilado. Se pareço inteiro, é a custa de recomposições de borracha. [...] Não estranhe minhas demoras em escrever - falta de veneta, de ânimo, pois você bem sabe como em mim a alegria por assim dizer social é sempre ou quase sempre um esforço deliberado contra a acídia. Escrevame sempre uma linha ou outra, acompanhando seus artigos, seus belos e fortes artigos desta sua nova fase $[\ldots] .18$

A imagem do alter ego é configurada, portanto, num discurso do limiar, como maneira de desviarse do esvaziamento comunicativo, da acídia, do tom agônico, do silêncio que ronda o sujeito da escrita sentimento que aproxima o autor epistolar dos desafios do indivíduo desamparado de que fala Cristóvão Tezza. O desencantamento com o mundo - afim à própria crise que ronda o Ocidente no período entre-guerras, sobretudo após o crash da Bolsa de Nova York de 1929 - ficaria ainda mais eloquente no Brasil depois da Revolução de 1930, que teria abalado boa parte das estruturas econômicas e políticas com base nas quais homens da mesma classe social de Freyre e Lins teriam orientado suas vidas. Nesse passo, cosmovisão pessoal e processo social amalgamam-se na seguinte missiva de 17 de dezembro de 1930, escrita como uma espécie de lamento do exílio:

12 Trata-se do historiador Sérgio Buarque de Holanda (1902-1982), amigo próximo de Freyre na década de 1920.

13 Referência a Alfredo da Rocha Viana Filho, o Pixinguinha (1897-1973), compositor, flautista e saxofonista, e a Patrício Teixeira (1893-1972), violonista e cantor.

${ }^{14}$ Trata-se do jornalista Prudente de Morais Neto (1904-1977).

15 Por Dodô, os autores se referiam a Geraldo Barrozo do Amaral, amigo de Manuel Bandeira.

${ }^{16}$ Referência ao escritor Ronald de Carvalho (1893-1935).

${ }^{17}$ Marta Cecilia Betancur ressalta que não há uma posição homogênea sobre a origem etimológica do conceito de persona, que pode ter vindo da palavra grega prosopon ou do latim per-sonare, verbo que significava "soar através de". "De ahí que pueda decirse que la máscara era el medio a través del cual se expresaba un sentido y resonaba la voz del alma, como ha sido interpretada por pensadores como Hannah Arendt." (BETANCUR, 1.sem. 2010, p. 130). Marcel Mauss, em texto clássico, por sua vez, já teria apontado a origem etrusca da palavra, apesar de a cultura latina solidificar a tradição: "Naturalmente, a explicação dos etimologistas latinos - persona vindo de per / sonare, a máscara pela (per) qual ressoa a voz (do ator) - foi inventada logo em seguida. [...] $\mathrm{O}$ fato é que, materialmente, mesmo a instituição das máscaras, e em particular das máscaras ancestrais, parece ter tido por núcleo principal a Etrúria. [...] Mas, se não foram os latinos que inventaram a palavra e as instituições, ao menos foram eles que lhe deram o sentido primitivo que veio a ser o nosso. Eis o processo." (MAUSS, 2003, p. 386). Sobre o assunto, Norbert Elias é peremptório: "A persona latina referia-se a algo muito específico e tangível. Dizia respeito, antes de mais nada, às máscaras dos atores, através das quais eles proferiam sua fala. Alguns estudiosos inclinam-se para a visão de que a palavra persona derivaria do verbo personare, 'ressoar, soar através de'. Isso é possível, mas não passa de conjectura." (ELIAS, 1994, p. 131.).

${ }_{18}$ Carta de Gilberto Freyre a José Lins do Rego, com datação "31 de março de $1927 "$ 
Ninguém mais vivo nas minhas saudades do que você em quem estou sempre a pensar. Espero que tudo já lhe esteja correndo bem - o melhor possível. Creio aliás que a você a cousas não chegaram com a violência do Recife - onde andou solto pelas ruas um cachorro danado a fazer as vezes do velho Leão do Norte, decerto alheio a essa história de saques, que não constam do seu pedigree. Aqui estou como um emigrado qualquer - num exílio com todas as suas características de frio, dificuldade de dinheiro, incertezas. Em Lisboa não faz o frio dos países do Norte - mas para mim é pior porque é úmida, o que é ruim para os nervos. E meus nervos eu estou admirado de os estar contendo tanto e às vezes penso que se não posso mais. Tenho sofrido de insônia e quando durmo é para sonhar um sonho por cima do outro; sonhos cheios de gente conhecida e desconhecida, tudo sem nexo. Mas vou atravessando - tudo o melhor que posso. Se vem de Deus isso, que se faça a sua vontade, embora às vezes eu me sinta como um personagem colocado por engano do autor [...] num romance sentimental a que não pertence. ${ }^{19}$

O tom trágico, às vezes remediado pela fina ironia, ronda tanto a história do indivíduo quanto o próprio destino do país. Se os anos 1920 teriam instilado algum otimismo, os anos 1930 começariam de modo soturno para essa geração de escritores e intelectuais. Ora melancólico, ora nostálgico, José Lins estabelece um canal epistolar com Freyre em que a tristeza não é amainada; pelo contrário, atravessa os anos um pendor confessional a reclamar a falta, a carência, a crise, que contagia a própria maneira como concebe a rede de sociabilidade à qual pertence, em torno da livraria e editora dirigida por José Olympio, seu grande amigo e compadre. Leia-se uma carta de 1937 de Freyre a Bandeira:

Estou com saudade de você, das Blank, de Prudente, de Gastão, do nosso grande Rodrigo, dos renegados Lins e Jardim que me parecem agora de corpo e alma da Metrópole. Eu, Baby, é que me sinto cada vez mais daqui. Já me parece alguma coisa de freudiano, de regresso, alguma coisa assim. ${ }^{20}$

Bandeira mostra a carta a Lins, que frequenta sua casa. A resposta de José Lins não tarda:

Li a sua carta para o Bandeira onde apareço como um renegado. Foi a primeira vez que me deram o adjetivo. 'O renegado Lins'. Afinal de contas é o que me tem custado viver na metrópole: o desprezo dos amigos

${ }^{19}$ Carta de Gilberto Freyre a José Lins do Rego, com datação "17 de dezembro de 1930".

${ }^{20}$ Carta de Gilberto Freyre a Manuel Bandeira, com datação "Recife, 11 de fevereiro de 1937"

${ }^{21}$ Carta de José Lins do Rego a Gilberto Freyre, com provável datação “1937".

22 Carta de Gilberto Freyre a Manuel Bandeira, com datação "ApipucosRecife, 17 de agosto de 1943". que me são mais caros. Mas que hei de fazer? Tenho lhe escrito cartas sem respostas. Já nem conto mais. [...] Por que não manda uma linha ao renegado? Que diabo, um coração de pernambucano é tão duro assim? [...] Nada de coração de pedra mármore. Prefiro os corações de lama. ${ }^{21}$

Apesar das evidentes afinidades entre Freyre e José Lins, aqui fica claro que havia diferenças de temperamento que, ademais, podem corresponder à própria concepção de escrita um tanto diversa entre ambos, o que permite retomar a expressão "antagonismos em equilíbrio", citada no início desta seção. Os dois certamente têm uma prosa que "se esparrama", uma escrita carregada de tintas fortes, que oscila entre uma percepção da dureza da análise objetiva e a ductilidade amolecida que se aproxima de certo discurso (de linhagem romântica) tendente ao lírico, à expressão da subjetividade. Nas cartas, porém, é possível notar que, enquanto Lins é mais confessional e até complacente com relação às investidas do amigo, dirigindo-se ao parceiro pouco mais velho com certa reverência humilde, Freyre é mais "secarrão", como diria o próprio sociólogo em carta: "Nós, nesta família Freyre, somos uns secarrões na aparência, com um pudor exagerado da ternura, mas no íntimo uns grandes afetivos, uns sentimentais, muito presos um ao outro." 22 $\mathrm{O}$ adjetivo "renegado", além de indicar um sentimento de deslocamento na capital federal, funciona para Lins como uma oportunidade para mostrar-se cônscio desse descompasso, entre o "coração de pedra mármore" de um e o "coração de lama" do outro. Note-se, inclusive, a referência a termos ligados à terra: a lama e a pedra. A terra e seus complexos, como a "província" e o elemento "telúrico", aliás, são muitas vezes utilizados por ambos para comporem movimentos tensivos que signifiquem a distância com relação aos valores ligados ao iluminismo, ao racionalismo burguês, tendente ao apagamento do eu, à figuração subjetiva "desprovida de nós". Contudo, mesmo dentro daquela identidade mais telúrica, haveria diferenças: um mais seco e contido, o outro mais úmido e derramado. De qualquer modo, a expiação ofereceria a tônica desses discursos epistolares, sobretudo da parte de José Lins, que conseguiria, como poucos, fazer um lamento literário impactante sobre o mundo nordestino em decadência, como em Menino de Engenho, de 1932, e Fogo Morto, de 1943. Seu diálogo com Freyre, ademais, reforça um vínculo em que ele pode se expressar de modo eloquente, falando sobre fraqueza, sentimento de culpa, medo da vida e da morte, sobre o temor de que o rosto, a máscara relacional, se estilhace sem possibilidade de recomposição.

De qualquer modo, a expressão subjetiva tendente ao encrespamento, à consternação e ao ensimesmamento por parte de José Lins não exclui momentos de expansividade. 
O distanciamento irônico também contribui para recuperar a comunicabilidade, dando-lhe um novo aprumo. Nesse sentido, cômico e trágico podem combinar-se, resultando em figurações da província carregadas de compaixão, vitalidade e desalento, paradoxalmente, como um Vitorino Papa-Rabo, personagem de Fogo Morto. Para encerrar esta seção, observe-se trecho de carta de José Lins a Freyre, com datação provável em " 24 de maio de 1943”, em que o capitão Vitorino é apresentado como herói quixotesco:

\begin{abstract}
Meu querido Gilberto
Um grande abraço. Nada de bilhete azul, por parte do Cassiano. Pelo contrário, cada vez ele mais se manifesta amigo seu. O que houve foi safadeza da administração das Empresas, contra ele. Mas que ele venceu. Tanto é assim que ele me pede para levar uma transcrição de livro seu para completar os mil cruzeiros. Ontem acabei o meu novo romance. Nada lhe posso dizer. Fiz de herói do livro um bobo de engenho, o capitão Vitorino Carneiro da Cunha, vulgo Papa-Rabo. Não sei se consegui vencer as dificuldades, mas procurei dar ao meu velho Papa-Rabo, um relevo de Quixote dos canaviais. É um tipo que diz tudo o que sente e que de nada tem medo. Tudo se passa no engenho de Seu Lula, aquele engenho de que falo no Banguê e Menino de Engenho. O livro se chama Fogo Morto. A sugestão do engenho parado me dera o título. $[\ldots]^{23}$
\end{abstract}

\section{Máscaras epistolares na modernidade: da província à nação}

Por meio deste ensaio, esperamos ter mostrado como pensar a dinâmica das máscaras, ou das personae, é produtiva, em especial na correspondência, para se compreenderem movimentos da configuração específica de uma certa modernidade na província, empreendida por escritores como Gilberto Freyre, José Lins do Rego e Manuel Bandeira. Ainda mais, em determinados momentos, sobretudo na década de 1930, essa disposição para a composição de perfis acabou por influenciar também gestores de políticas públicas voltadas para a cultura, como seria o caso de Rodrigo Melo Franco de Andrade, amigo de Freyre a apoiar, com dedicação, a escrita de Casa-grande \& senzala no início dos anos 1930.

Gilberto Freyre mostra, no limite, como o epistológrafo constrói diferentes faces ou perfis de acordo com seu correspondente. Essa disposição não é dada de antemão, mas construída na própria dinâmica da troca de cartas, embora demonstre, em muitos momentos, certa carência de discursos integrais, a perseguir conceitos com

\footnotetext{
${ }^{23}$ Carta de José Lins do Rego a Gilberto Freyre, com datação "24 de maio de $[1943] "$.
}

o "autêntico" e a "origem" ou a "formação". Cartas com Bandeira e Rodrigo Melo Franco de Andrade manifestam como o cosmopolita outsider lança-se num jogo dinâmico de personae procurando configurar um discurso que indicasse as inúmeras camadas que sua "alma provinciana" poderia abarcar. Explorando figuras de linguagem como o paradoxo, essa disposição comunica-se com a imagem de Brasil que o escritor propagaria na década de $1930 \mathrm{em}$ diante, homogêneo em suas contradições indissolúveis, em sua heterogeneidade constitutiva, misto de tradição e modernidade, rural e urbano, atraso e progresso, província e cosmópolis.

Quando destaca a necessidade dos espectadores epistolares e elabora personae que poderiam levar a uma apreensão do seu "verdadeiro eu", mutilado e recomposto, Gilberto Freyre curiosamente se coloca, de modo instável - pelo menos nessa correspondência das décadas de 1920 e 1930 -, a meio caminho entre uma visão exterior e relacional das personae, presente no mundo clássico, e uma concepção metafísica da pessoa, do homem: apesar da viabilidade das máscaras sociais, das manifestações particulares que ressoam significativamente na vida pública, haveria um valor intrínseco que dignificaria a individualidade do homem moderno. Nesse sentido, converge para a própria reformulação pela qual o termo tem passado na contemporaneidade: "Cuando decimos de alguien que 'no enseña su verdadera cara' [...], estamos hablando como sujetos modernos que perciben el rosto, a la vez, como lugar del ser y la apariencia, como lugar de la esencia y el fingimiento, de la verdad misma y el artificio." (ALTUNA, 2010, p. 39). Assim, tanto a dinâmica relacional quanto a perspectiva substancialista são postas em questão, e seus limites são evidenciados por meio da expressão individual em interação epistolar com o outro. O rosto seria "el lugar, en definitiva, en que el alma se muestra e y se disfarza" (ALTUNA, 2010, p. 39). Tende, inclusive, à elaboração de uma espécie de figuração balanceada entre o eu e o nós, acachapada pela tradição metafísica moderna que tenderia a privilegiar o indivíduo em detrimento do social, como indica o próprio Freyre em sua obra.

Desse modo, na periferia em relação ao epicentro do poder político e econômico - situado entre Rio de Janeiro e São Paulo -, Freyre e outros provincianos teriam elaborado um discurso alternativo de modernidade, pautando-se pela infância, pelo resgate da experiência, pelo passado, pela vida no campo, pela dinâmica social herdada do mundo rural e influenciada pelas relações familiares de origem patriarcal. Esse discurso alternativo, a acastelar um mundo decadente e relativizar a validade das grandes utopias ocidentais de igualdade e liberdade, acabaria por desafiar as proposições mais francamente racionalistas e abstratas como ideal de modernização do 
país, buscando, ao fim, equilibrar, de modo sui generis, o indivíduo e o coletivo.

Do ponto de vista literário, combinados com traços sobretudo trágicos, Freyre na interlocução com José Lins utiliza menos o jogo de máscaras a dialogar com a teatralização clássica, se comparado ao discurso mais carnavalizado que engendra com Bandeira. Porém, o impulso para compor uma imagem do sujeito epistolar, os traços instáveis de um rosto, parece a todo instante se confrontar com a ideia de esvaziamento, explosão, morte, dissolução da máscara social e relacional. A possibilidade de reconhecimento do rosto integral, de interação e intercomunicação, é questionada. Desenhamse, assim, personagens dilacerados pelos movimentos da vida moderna, que dispensam o mito da unidade e autossuficiência do sujeito, cujo rosto, sobrevivente, seria suporte, instável mas sempre renovado, para uma comunicação constantemente ameaçada. Na utopia de uma comunicação possível, apesar das ameaças de atomização do indivíduo e de seu silenciamento, situa-se o debate na província.

E, visto em perspectiva, a meio caminho entre a exterioridade das máscaras e a interioridade do sujeito moderno, Freyre não deixa de flertar com concepções contemporâneas e pós-modernas que estilhaçam a unidade de fundo para enfatizar o rosto como suporte para "inúmeras caretas", superfície sem substância. ${ }^{24}$ Essa imagem seria uma antecipação do próprio sujeito mediático Freyre, espetacularizado, pós-moderno, que atuaria de modo mais forte na segunda metade do século. A leitura da obra tardia de Freyre pode ganhar se vista por esse ponto de vista, quando, inclusive, é publicado o seu diário Tempo morto e outros tempos (1975). ${ }^{25}$

Assim, nas missivas das décadas de 1920 e 1930, Gilberto Freyre sintomaticamente dinamiza ao redor de sua figura um conjunto de atributos que, combinados em perspectiva, remeteria a posteriori para a imagem singular e personificada de Brasil moldada em Casagrande \& senzala, como uma síntese de antagonismos em tensão. ${ }^{26}$ Nas cartas, inclusive, Freyre joga não somente máscaras do eu, mas também se envolveu na tentativa de elaborar rostos para uma nação permeada de contrastes, para um Brasil que buscava modernizar suas estruturas. ${ }^{27} \mathrm{~A}$ correspondência, nesse sentido, também pode ser um laboratório para a construção de perfis nacionais pautados pela origem cultural diversa. $\mathrm{E}$ ainda, vale lembrar, num contexto em que "intelectuais ligados ao poder público passavam a pensar em políticas culturais que viabilizassem "uma autêntica identidade brasileira"” (SCHWARCZ, 1994, p. 13), Casa-grande \& senzala ocupou um lugar único ao exaltar a singularidade da mestiçagem, tingindo o perfil peculiar de um rosto - com sua carga de inequívoca homogeneização, embora reconhecendo os inúmeros "antagonismos em tensão" - que representasse uma sociedade multirracial.

Nesse sentido, a própria dialética de mascaramento e desnudamento encontra correlação na imagem de país que o autor constrói a partir da década de 1930 desnudamento pela ação da memória, que revela, por exemplo, a dinâmica sadomasoquista intrínseca à relação entre senhores e escravos; e mascaramento, por meio do processo de tipificação que agrega o plural, tocando a forma da caricatura e do estereótipo, apesar de empreender uma persistente busca pela singularidade. São desafios modelarmente assumidos pelo autor, para serem lidos por uma sociedade de massas, cada vez mais complexa, espécie de agregação de indivíduos que, paradoxalmente e por contraste, não dispõe, no todo ou na parte, de um rosto unificador.

24 Para Belén Altuna: "Algunas de estas tendencias modernas retoman el origen teatral de persona para subrayar el carácter de la existencia humana como theatrum mundi y de los individuos como actores que representan distintos papeles en diferentes situaciones, en los tribunales de justicia o en los rituales de sociedad no menos que en los escenarios. Según esta perspectiva, nuestra cara sería una careta, o mejor, un soporte para múltiples caretas [...]" (ALTUNA, 2009, p. 39). O exemplo que a autora cita é o estudo de Erving Goffman $A$ representação do eu na vida cotidiana (1985), para quem uma maneira de se articularem personalidade, interação e estrutura social é por meio dos estudos da representação: "Uma cena corretamente representada conduz a plateia a atribuir uma personalidade ao personagem representado, mas esta atribuição - este 'eu' - é um 'produto' de uma cena que se verificou, e não uma 'causa' dela. O 'eu', portanto, como um personagem representado, não é uma coisa orgânica, que tem uma localização definida, cujo destino fundamental é nascer, crescer e morrer; é um efeito dramático, que surge difusamente de uma cena representada [...]" (GOFFMAN, 2002, p. 231).

25 Segundo a historiadora Maria Lúcia Pallares-Burke, o diário de Gilberto Freyre Tempo morto e outros tempos seria, na verdade, não um diário propriamente dito, mas uma autobiografia em forma de diário: “[...] fica claro que o texto foi escrito e reescrito ao longo dos anos, houvesse ou não um núcleo original de entradas feitas na própria época dos eventos que descreve. Quando se comparam, por exemplo, alguns fatos ali narrados com o que outros documentos comprovadamente de época revelam, o caráter memorialístico de Tempo morto fica evidente" (PALLARES-BURKE, 2005, p. 25). Gostaríamos, citando-o neste preciso momento, de destacar o aspecto construtivo ou performático na obra do ensaísta.

26 Belén Altuna aponta para o movimento moderno de abandono do rosto singular, único, e retomada das personae romanas que aproximaria o rosto do que eu chamaria de estereotipias da modernidade: "Esa sociedad de masas tecnificada y, posteriormente, esa sociedad de la imagen y del consumo, habría privilegiado la mirada técnica-objetiva-conceptual que transforma la cualidad en cantidad, el rostro en número, en estereotipo; en definitiva, en máscara. Las teorías del rol para explicar nuestras interacciones sociales parten también de ese principio: anuncian que en esas interacciones tratamos con máscaras - clases de máscaras, estereotipos, como aquellas personae romanas - más que con rostros singulares, únicos." (ALTUNA, ago. 2009, p. 50).

27 Nesse sentido, cf. trecho de carta de Freyre a Gustavo Capanema, com datação "Assunção, Paraguai, 31 de janeiro de 1942”: "A ideia do monumento ao índio - uma de suas esplêndidas ideias - será recebida com entusiasmo em toda a Indo-América, que também começa a sentir - e com razão - que o nosso Vargas é um dos seus leaders. Por que não ser o monumento, a figura de Indo-América? O Celso poderia fazer coisa magnífica. E teria uma mística mais poderosa que a do índio." (SCHWARTZMAN, 2000, p. 339). 


\section{Referências}

ALTUNA, Belén. El individuo e sus máscaras. Ideas y valores, Bogotá, n. 140, p. 33-51, ago. 2009.

ALTUNA, Belén. Una historia moral del rosto. Valencia, España: Pre-Textos, 2010.

BANDEIRA, M. Sou provinciano. In: Poesia completa e prosa. Rio de Janeiro: Nova Aguilar, 1974.

BAKHTIN, Mikhail. A cultura popular na Idade Média e no Renascimento: o conceito de François Rabelais. Trad. Yara Frateschi Vieira. São Paulo/Brasília; Hucitec/UnB, 1987.

BAKHTIN, Mikhail. Problemas da poética de Dostoiévski. Trad. Paulo Bezerra. Rio de Janeiro: Forense-Universitária, 1981.

BENJAMIN, W. A obra de arte na era de sua reprodutibilidade técnica. In: Magia, técnica, arte e política. Trad. Sérgio Paulo Rouanet. São Paulo: Brasiliense, 1985.

BERARDINELLI, A. Da poesia à prosa. Org. Maria Betânia Amoroso; Trad. Maurício Santana Dias. São Paulo: Cosac Naify, 2007.

BETANCUR, M. C. Persona y máscara. Praxis Filosófica, Cali, Colombia, n. 30, p. 127-143, $1^{\circ}$ sem. 2010.

CARPEAUX, Otto Maria. As revoltas modernistas na literatura. Rio de Janeiro: Ediouro, [s.d.].

DERRIDA, Jacques. The politics of friendship. London, New York: Verso, 2005.

ELIAS, Norbert. A sociedade dos indivíduos. Org. Michael Schröter; trad. Vera Ribeiro; revisão técnica e notas Renato Janine Ribeiro. Rio de Janeiro: Jorge Zahar, 1994.

GOMES, Ângela de Castro (Org.). Em família: a correspondência de Oliveira lima. Campinas: Mercado Aberto, 2005.

FREYRE, Gilberto. Cartas do próprio punho sobre pessoas e coisas do Brasil e do estrangeiro. Seleção, organização e introdução de Sylvio Rabello. Rio de Janeiro: Conselho Federal de Cultura, 1978.
FREYRE, Gilberto. Sobrados e mucambos: decadência do patriarcado rural e desenvolvimento do urbano. São Paulo: Global, 2003.

GOFFMAN, Erving. A representação do eu na vida cotidiana. Trad. Maria Célia Santos Raposo. Petrópolis: Vozes, 1985.

GUIMARÃES, Julio Castañon. Contrapontos: notas sobre correspondência no modernismo. Rio de Janeiro: Fundação Casa de Rui Barbosa, 2004.

MAUSS, Marcel. O sujeito: a pessoa. In: Marcel Mauss: Sociologia e antropologia. Trad. Paulo Neves. São Paulo: Cosac \& Naify, 2003. p. 369-398.

PALLARES-BURKE, Maria Lúcia. Gilberto Freyre: um vitoriano dos trópicos. São Paulo: Ed. UNESP, 2005.

SCHWARCZ, Lilia. Complexo de Zé Carioca: sobre uma certa ordem da mestiçagem e da malandragem. Trabalho apresentado ao XVIII Encontro Anual da ANPOCS. Caxambu, Minas Gerais, 1994.

SCHWARTZMAN, Simon; BOMENY, Helena Maria Bousquet; COSTA, Vanda Maria Ribeiro. Tempos de Capanema. São Paulo: Paz e Terra; Fundação Getúlio Vargas, 2000.

SOUZA, Jessé. A modernização seletiva: uma reinterpretação do dilema brasileiro. Brasília: Editora Universidade de Brasília, 2000 .

TEZZA, Cristovão. O espírito da prosa. Rio de Janeiro: Record, 2012.

VICENTE, Silvana Moreli. Cartas provincianas: correspondência entre Gilberto Freyre e Manuel Bandeira. 2008. Tese (Doutorado em Letras) - Faculdade de Filosofia, Letras e Ciências Humanas, Universidade de São Paulo, São Paulo, 2007.

Recebido: 30 de outubro de 2013

Aprovado: 28 de novembro de 2013

Contato: silmoreli@usp.br 